\title{
Percepción de las variedades del español por parte de los estudiantes de Lengua y Literaturas Hispánicas de la Universidad de Zagreb
}

\section{Introducción}

En este artículo se analizarán las percepciones sobre las variedades del español por parte de los estudiantes de Lengua y Literaturas Hispánicas de la Universidad de Zagreb. Hemos elegido tal grupo de informantes porque son los que tienen conocimientos profundos de la lengua española, por ser esa su carrera universitaria. Aún más, se trata de personas que al salir de la universidad irán diseminando sus conocimientos sobre la lengua española en un campo especializado o científico como futuros especialistas en lingüística española. Por lo tanto, nos pareció oportuno llevar una investigación dentro de esa población, estadísticamente relevante. El tema nos resultaba relevante porque se mostró que entre los no hispanohablantes existe la opinión general de que existe una lengua culta. La investigación (en forma de un cuestionario en línea) fue hecha en dos partes. En la primera parte los estudiantes fueron inquiridos sobre sus conocimientos lingüísticos y enciclopédicos de la lengua española, p. ej. dónde se habla español como L1, cómo definen el español estándar, cómo perciben las variedades del español en Hispanoamérica, etc. En la segunda parte los estudiantes tuvieron que evaluar y reconocer diferentes variedades del español hablado, escuchando unas grabaciones auténticas, hechas por nativos. Como no fue posible mostrar todos los datos obtenidos durante la encuesta por su exhaustividad, hemos optado por exponer la parte que trata el tema de la lengua estándar y de las variedades habladas del español. Por otro lado, la parte en la que se quiso averiguar si los estudiantes son capaces de reconocer de qué variedad de español se trata, o como evalúan tal variedad será analizada en próximos trabajos. 


\subsection{Actitudes lingüísticas}

Moreno Fernández (2009: 178) define la actitud lingüística como una «manifestación de la actitud social de los individuos, distinguida por centrarse y referirse específicamente tanto a la lengua como al uso que de ella se hace en sociedad $[. .]$.$» .$

En este artículo se valorarán el concepto de actitud y el de creencia (Blas Arroyo, 2005; García, 1993), asociando las creencias con la conciencia lingüística, o sea, con los conocimientos (reales o no) que tienen los informantes sobre la lengua y como la perciben.

La misma lengua o su variedad no son necesariamente motivos para la aparición de una actitud hacia la lengua, sino que sus hablantes en cierto contexto sociolingüístico evocan las reacciones en los miembros de las demás comunidades de habla (Erdösová, 2011). Por estas razones el objetivo del trabajo era capturar el modo de pensar de los estudiantes porque la conciencia lingüística de los hablantes no siempre tiene una índole científica, sino refleja su manera de entender el mundo lingüístico que les rodea o que estudian.

\section{Español como lengua pluricéntrica}

Hoy día hablamos del español como de una lengua pluricéntrica, junto a la mayoría de las lenguas europeas que se han expandido durante la época de la colonización fuera de sus sedes y núcleos originarios. El español, del mismo modo que el inglés, el portugués o el alemán, se habla en diversos y, sobre todo, vastos territorios geográficamente no unidos, por lo cual es imposible esperar que todos los hablantes de la misma lengua hablen de la misma manera, lo que vienen mostrándonos varios estudios sociolingüísticos desde la segunda mitad del siglo pasado (Alvar, 1983, 1986; Lope Blanch, 1968, 1995; Moreno Fernández, 1992, etc.). Existen numerosos factores que influyen en la lengua y en sus usuarios. Por razones obvias resultaba imposible denominarlos todos con diferentes nombres, por lo cual se intentaron determinar los criterios según los cuales uno podría distinguir entre dos o más lenguas. Lamentablemente se trata de criterios poco fijos, ya que la lengua no es solo una cuestión lingüística, sino también política. Los idiomas simbolizan las identidades y se utilizan para indicar las identidades de quienes los hablan. La gente también es clasificada según la lengua que usa, y por eso a menudo se relaciona con la nacionalidad. En este sentido se puede decir que la identidad nacional es superior a la identidad personal y local, o que el individuo se identifica con 
los que pertenecen a la misma nación y se distancia de aquellos que no pertenecen a ella. En ese sentido la lengua no es puro medio de comunicación o de transmisión de la información lingüística, sino también tiene su función y significado social. Moreno Fernández (2005) destaca que la razón de la variación lingüística y sociolingüística, y de la conducta humana, yace en las creencias y actitudes de los hablantes, que estigmatizan o aceptan ciertos usos lingüísticos concretos como las variedades de una lengua o las lenguas que entran en contacto. A partir de la forma de hablar el hablante construye su identidad lingüística al ser miembro de una comunidad de habla por compartir ciertos rasgos y al diferenciarse de los grupos con rasgos divergentes. Esto se regula a través de la percepción que ayuda a analizar las semejanzas entre el propio grupo y las diferencias con el otro, si bien no se limita solo al plano lingüístico, sino que alude a ciertas actitudes (sociales o históricas) frente a la variedad percibida. A través de la lengua se estudian temas como la política lingüística, el prestigio, el bilingüismo, las categorías sociales, la educación lingüística, los estereotipos, la (in)seguridad y la conciencia lingüística, etc. La dirección en que evolucionará la lengua no se puede controlar ni anticipar, ya que su desarrollo depende de las actitudes de los hablantes. Se trata del conjunto de las actitudes, o sea, de todo lo que los hablantes piensan y saben sobre la lengua y su poder de articular ese saber (Schmid, 2014).

\subsection{Norma culta y variedades estándares}

España siempre estuvo dialectalmente dividida, no solo porque se trata de una lengua que se usa como $\mathrm{L}_{1}$ en 20 países, sino también porque en el mismo territorio de España existen grandes diferencias dialectales. Desde el comienzo de las conquistas coloniales hasta el siglo XIX, el idioma que sirve como base para todas las variedades, diatópicas o diastráticas, es la norma de la metrópolis (el castellano). Por lo que respecta al proceso de la estandarización del español moderno, todos los procesos ocurrieron en España y desde ahí fueron trasladados a los países de América. Sin embargo, la colonización empezó mucho antes que la estandarización, en una época en la que en España ya existían numerosas variedades, lingüísticamente igualitarias pero no económica y políticamente. García de Paredes (2012: 285) destaca que en España existe la opinión de que la pureza de la lengua se vincula estrechamente con el lugar de nacimiento del español, y de que esa pureza, con la expansión a otros territorios, se contaminó. De ahí surgen muchas polémicas. ¿Es el origen un factor privilegiado para una evaluación positiva de cierta variedad? ¿O hay que considerar 
el número de hablantes como el criterio prevalente? Aunque en la bibliografía a menudo se pueden encontrar datos en los que las variedades del español son descritas como desviaciones lingüísticas, hay que tener en cuenta que ciertas variaciones lingüísticas en América representan el estándar, es decir, se trata de formas de ninguna manera diatópicamente marcadas (en esos territorios), por lo cual allí son la base y la norma. Por eso no deben ser consideradas como desviaciones, sino como la representación del estándar regional.

Haugen (1966) nombra cuatro pasos en el proceso de estandarización, donde el primero es la elección de la norma y el último la aceptación de la misma por parte de la comunidad lingüística. En Europa, la mayoría de las lenguas ya está normativizada. Esta norma se basa en el heredado sistema normativo tradicional, pero la norma del inglés, por ejemplo, se basa en el uso hablado por cierta élite (ing. Received Pronunciation). En la mayoría de los casos se trata de la forma de hablar de los hablantes educados, considerados como portadores del prestigio en una comunidad lingüística. Lope Blanch (1995) destaca que en cada país del territorio hispano existe una norma adecuada a la cual los hablantes intentan acercarse cuando quieren hablar correctamente. Por eso se suele vincular la norma culta con la hablada según los habitantes de la capital, por ejemplo, el madrileño en el caso de España, el limeño en el caso del Perú, etc.

\section{Metodología}

La encuesta está formada por un cuestionario y grabaciones de discurso oral en las variedades de español. En este trabajo se presentarán los datos del cuestionario que investiga los conocimientos y actitudes de los estudiantes de Lengua y Literaturas Hispánicas de la Universidad de Zagreb en cuanto al español y sus variedades.

El cuestionario fue elaborado a base de las encuestas hechas por Cestero, $\mathrm{Pa}$ redes (2015) pero adaptado al ámbito y a los propósitos propios ya que no se trata de hablantes nativos, por lo cual no se pidieron datos sociogeográficos de los estudiantes. Se quiso obtener datos sobre la valoración y las actitudes de los estudiantes hacia la lengua española y sus variedades a través de las preguntas abiertas y cerradas. Las preguntas abiertas se referían en la mayoría de los casos a su valoración del español y sus opiniones sobre el idioma mientras que las preguntas cerradas tematizaban sus conocimientos lingüísticos y extralingüísticos sobre el español y sus variedades. De todos modos, hay que destacar que el programa de estudio de grado no tiene incorporadas asignaturas de 
sociolingüística y dialectología, las cuales son obligatorias solo para los estudiantes que eligieron el módulo de lingüística en los estudios de máster. Sin embargo, a través de la literatura y de las clases que tienen con los lectores extranjeros, los estudiantes de grado pueden familiarizarse con ese tema, aunque sin una enseñanza sistemática.

\subsection{Los informantes}

El cuestionario fue completado de forma anónima y voluntaria en el período comprendido entre el 20 de abril y el 31 de abril de 2016 . Fue realizada por 154 estudiantes, de los cuales un $6,5 \%$ son varones ( 10 estudiantes) y un 93,5 \%, mujeres (144 estudiantes). La edad de los informantes va de los 18 a los 32 años, pero el promedio oscila alrededor de los 20: la media aritmética es de 21,8 , la moda es de 19 y la mediana de 22 (hay solamente 7 estudiantes que tienen más de 25 años). La mayoría de los informantes (55,2 \%) nació en Zagreb y en el resto en las grandes ciudades de Croacia (más del $5 \%$ de los estudiantes nació en Split [6,5\%] y en Dubrovnik [5,8 \%]). Además, 6 informantes nacieron fuera de Croacia. La lengua materna de todos los informantes es el croata y un informante es bilingüe (croata/alemán).

Todos los informantes estudian lengua y literaturas hispánicas en la Facultad de Humanidades y Ciencias Sociales de la Universidad de Zagreb: 92 informantes son estudiantes de grado, 51 son estudiantes de máster, y 11 de ellos están escribiendo su trabajo final de máster (Gráfico 1).

\section{¿En qué año de estudio está?}

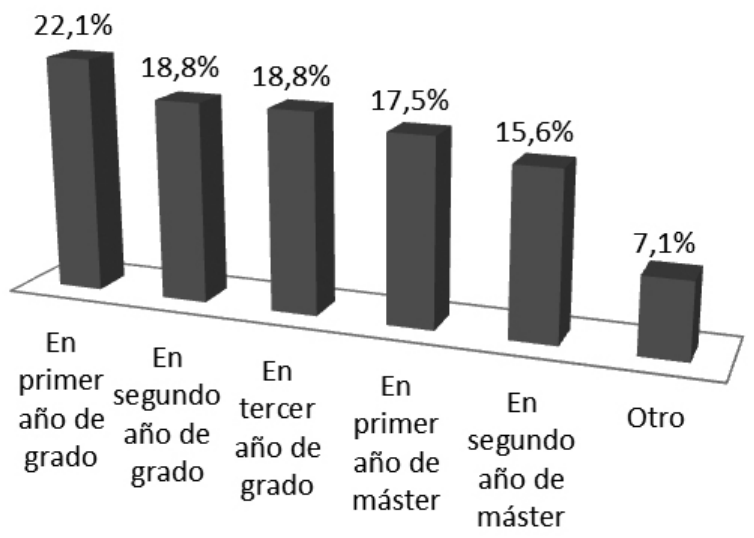

Gráfico 1. Distribución de los informantes según el año del estudio universitario 
Además de lengua y literaturas hispánicas, muchos informantes estudian lengua y literatura alemanas $(15,1 \%)$, inglesas $(7,9 \%)$ e italianas $(7,9 \%)$. Algunos estudian otras lenguas romances: francés $(7,2 \%)$, portugués $(3,3 \%)$ y rumano $(0,7 \%)$. En total, un $19,1 \%$ de los informantes estudia otra lengua romance junto con el español. Cabe mencionar también que un 6,6 \% de los informantes estudia croata, mientras que un 5,9\% estudia lingüística general.

\subsection{Resultados del cuestionario}

A continuación se ofrecerán los datos y resultados obtenidos por el cuestionario según el orden de las preguntas. La primera parte se refiere a los intereses y datos personales de los estudiantes y la segunda a sus conocimientos de las variedades del español.

\subsubsection{Datos personales y los intereses de los estudiantes}

La mayoría de los informantes $(61,7 \%)$ ha visitado un país hispanohablante una o más veces, mientras que el resto $(38,3 \%)$ nunca lo ha hecho. Cuando comparamos los estudiantes de grado con los de máster, hay más estudiantes de máster que han visitado un país hispanohablante dos o más veces. Asimismo, en el máster disminuye el número de estudiantes que nunca han visitado un país hispanohablante o los que lo han visitado solamente una vez. Curiosamente, solo una persona ha visitado dos países de Hispanoamérica y nunca ha estado en España. Cuatro informantes más han visitado, además de España, algún país de Hispanoamérica (Ecuador, México, Costa Rica, Argentina, Uruguay y Cuba). En total, el 5,3\% de los estudiantes ha visitado algún país de Hispanoamérica.

Los informantes están muy interesados en la cultura que proviene de los países hispanohablantes: un 98,7 \% de ellos escucha música, ve películas y lee libros que provienen de España o de Hispanoamérica, mientras que un 91,5\% consulta medios de comunicación en español. En cuanto a los medios de comunicación, los informantes prefieren consultar sitios web, seguidos de redes sociales y periódicos y, finalmente, programas de radio y de televisión (Gráfico 2).

A los informantes les importa más saber de dónde provienen la música, las películas y los libros en español $(76,2 \%)$ que los medios de comunicación $(58,7 \%)$. A la pregunta de dónde provienen esa música, esas películas, esos libros y esos medios de comunicación, el orden de las respuestas es el siguiente: 
¿Qué medios de comunicación consulta?

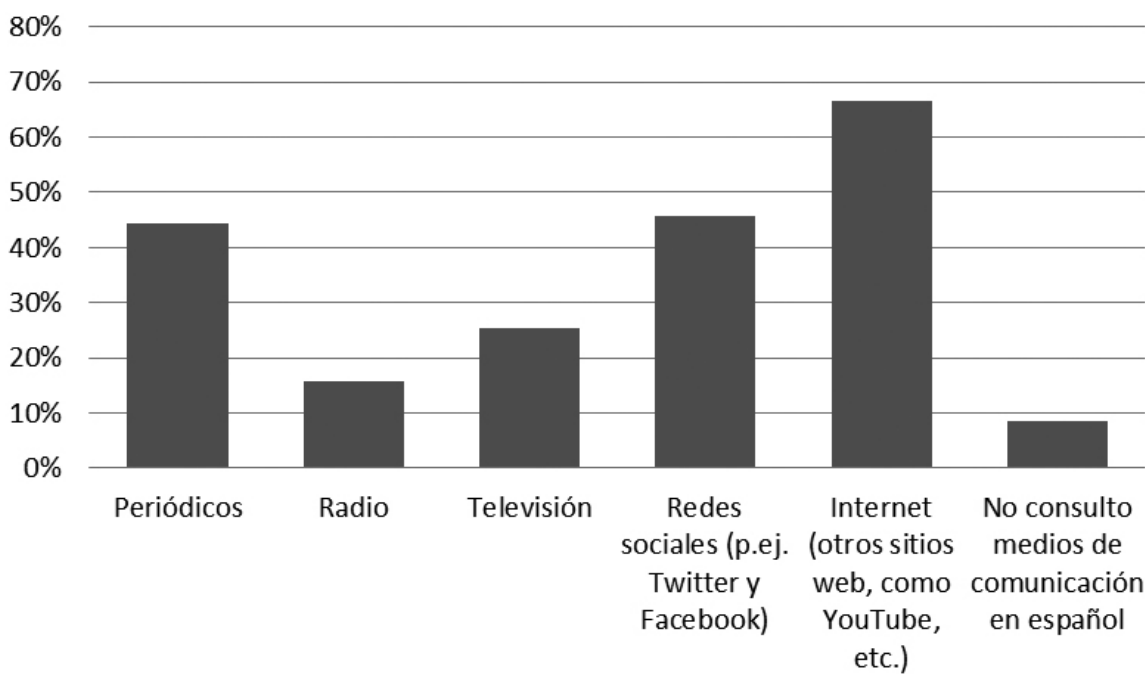

- Los estudiantes de grado y de máster

Gráfico 2. ¿Qué medios de comunicación consulta?

en el primer lugar está España (93,6 \% para la música, las películas y los libros, 91,1 \% para los medios de comunicación), y luego Argentina, México, Colombia y Cuba. El resto de países está mucho menos representado. Además, hay algunos países que no fueron seleccionadas ni una sola vez (El Salvador, Honduras, Panamá, Paraguay y Uruguay para la música, las películas y los libros, y Costa Rica para los medios de comunicación).

\subsubsection{Los conocimientos de las variedades españolas e hispanoamericanas}

En esta parte se expondrán los resultados que se refieren a los conocimientos lingüísticos y extralingüísticos de los estudiantes de Zagreb.

\section{(1) Los paises donde el español es idioma oficial}

A la respuesta sobre el número de países donde se habla español como primera lengua (Gráfico 3) respondieron 71 estudiantes de grado y 50 estudiantes de máster. Las respuestas de los informantes de grado van desde 2 hasta 30 países. 
La media aritmética es de 18,7 , mientras que la moda y la mediana son iguales a 20. Más de un tercio de los estudiantes (33,8\%) opinan que el español es idioma oficial en 20 países, la respuesta correcta. En cuanto a los estudiantes de máster, sus respuestas van desde 10 hasta 25 países. La media aritmética es de 19,72, mientras que la moda y la mediana son iguales a 20 otra vez. 21 estudiantes de máster ( $42 \%$ ) respondieron correctamente a esta pregunta. La aplicación de test $\mathrm{T}$ ha confirmado, con una seguridad del $95 \%$, que la diferencia entre los informantes de grado y de máster es estadísticamente significativa $(t=-1,60332<1,96)$.

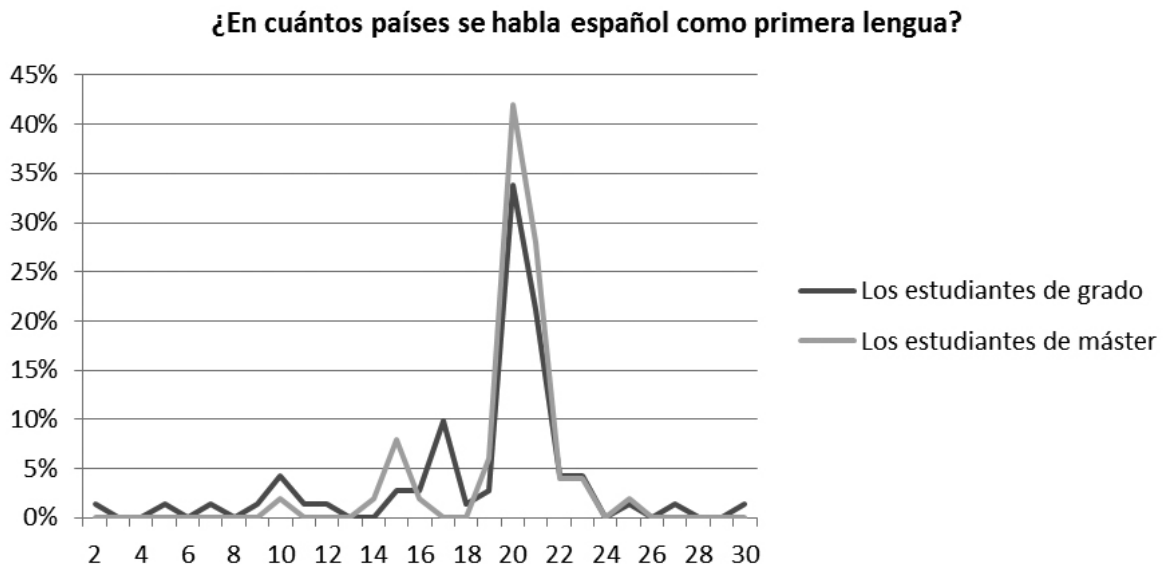

Gráfico $3 \cdot$ ¿En cuántos países se habla español como primera lengua?

\section{(2) Las variedades del español peninsular}

En el Gráfico 4a se pueden ver las respuestas a la pregunta sobre las variedades del español peninsular. Como se trata de una pregunta abierta, los informantes pudieron enumerar todas las variedades que quisieron. Respondieron 60 estudiantes de grado y 41 estudiantes de máster. Los informantes ofrecieron muchas respuestas diferentes que luego fueron agrupadas bajo las 17 categorías que figuran en el gráfico. Mediante el gráfico se puede constatar que muchos informantes, tanto de grado como de máster, no diferencian las variedades del español habladas en España. En cuanto a las respuestas de los estudiantes de grado, sobresale el caso del catalán, que se menciona con mayor frecuencia. Siguen el gallego, el vasco y el castellano. Los estudiantes de máster mayoritariamente proponen la variedad andaluza y luego siguen el gallego, el catalán y el castellano. 


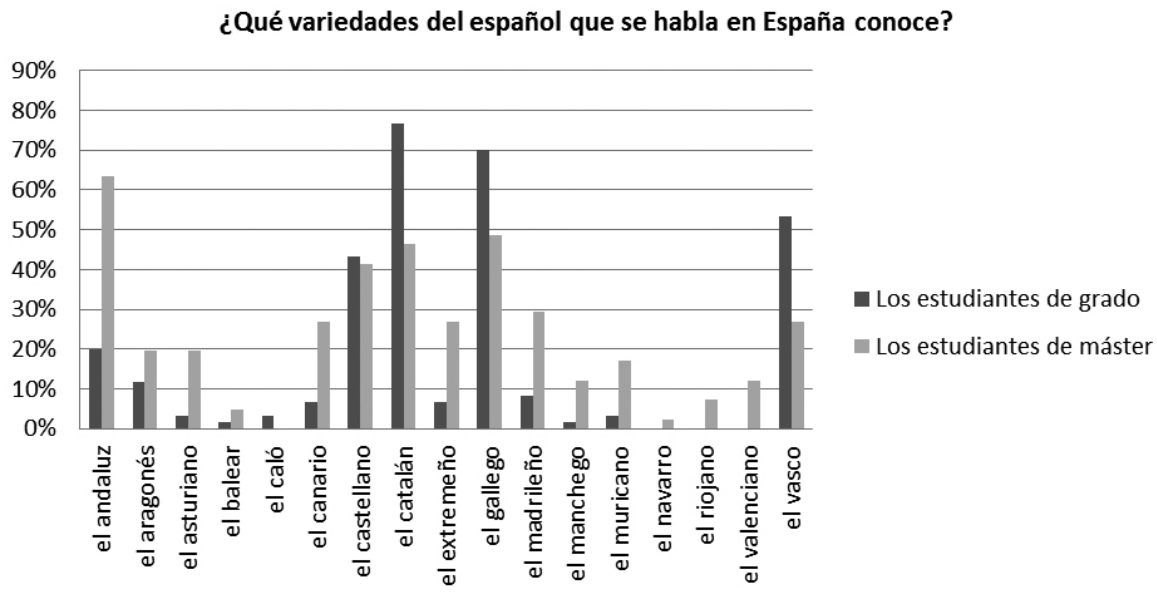

Gráfico 4a. ¿Qué variedades del español que se habla en España conoce?

Estos resultados también muestran una inseguridad lingüística por parte de estudiantes que enumeraban las lenguas cooficiales habladas en España (confundiéndolas obviamente con los dialectos del español) y no las variedades de la lengua española. Por eso queríamos ver si hay cambio respecto a la pregunta según los años del estudio. En el Gráfico 4 b se muestran los resultados divididos por el año del estudio.

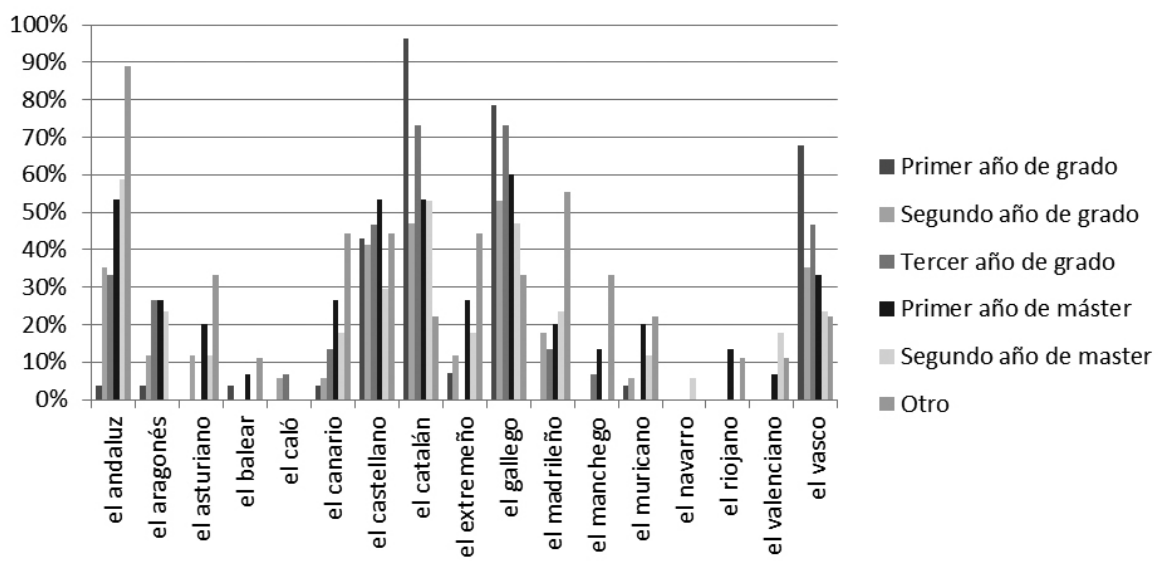

Gráfico 4b. La relación entre el año del estudio respecto al conocimiento de las variedades del español.

Del gráfico se nota que la mayoría de los estudiantes que consideran el catalán, el vasco y el gallego como una variedad del español son de primer año de 
grado. Con el avance en el estudio, especialmente en el máster, se puede ver que los estudiantes tienen más conocimientos sobre las variedades del español y que cae el número de los que consideran los idiomas cooficiales hablados en España como variedades del español. Lo que sí se destaca es el resultado del tercer año porque entre ellos el porcentaje de los que contestaron incorrectamente a esta pregunta crece de nuevo. De todos modos esta pregunta muestra que el tema de dialectología y sociolingüística debe ser implementado en las clases universitarias.

\section{(3) El español más correcto en España}

Un poco menos de la mitad de los estudiantes de grado (45,3 \%) consideran que existe algún lugar en España donde se habla mejor el español. La mayoría, por lo tanto, opina que no existe un español más correcto. Las opiniones de los estudiantes de máster no son muy diferentes: el 42,6 \% piensan que hay un lugar en España donde se habla más correctamente, mientras que el 57,4\% opinan que no es así (Gráfico 5).

\section{¿Considera que hay un lugar en España donde se habla el español más correcto?}

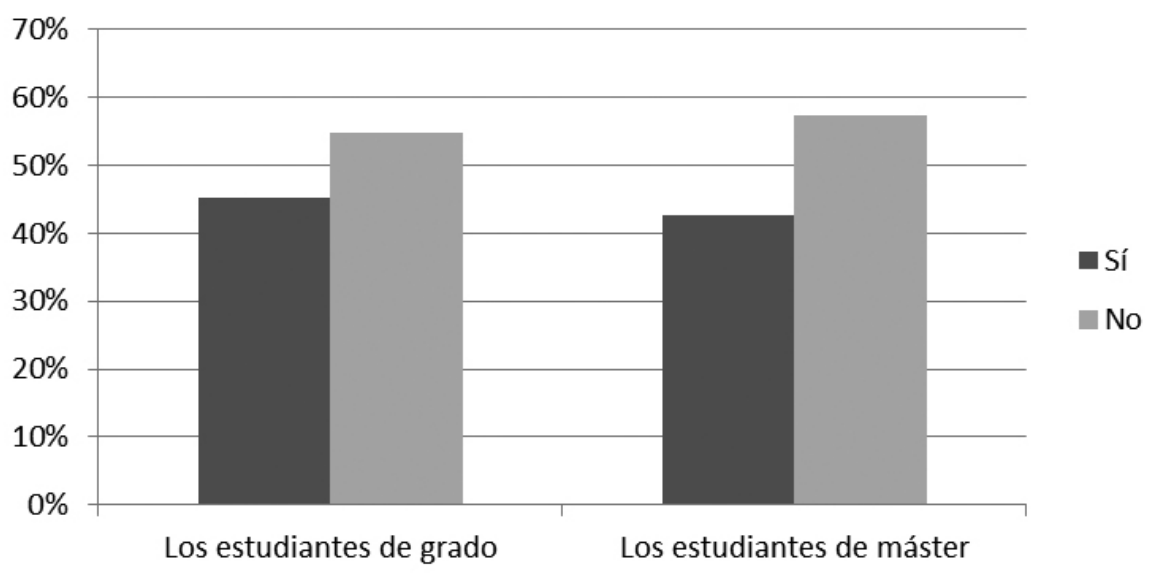

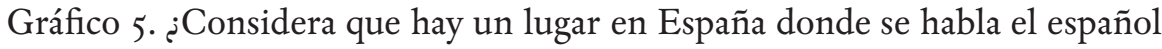
más correcto?

Treinta y un estudiante de grado y 21 estudiante de máster decidieron ejemplificar de qué parte de España concretamente se trata (Gráfico 6). La mayoría de ambos grupos consideran que se habla más correctamente en Madrid (51,6 \% para los estudiantes de grado y 27,1 \% para los estudiantes de máster) y luego 
siguen las comunidades autónomas Castilla-La Mancha y Castilla y León. Un pequeño porcentaje de los estudiantes de grado consideran que el español se habla mejor en Cataluña (9,7\%). Las respuestas que surgieron solamente una vez (como Aragón y Andalucía) no figuran en el gráfico.

\section{Si considera que hay un lugar en España donde se habla el español más correcto, escriba el nombre de la ciudad o de la región.}

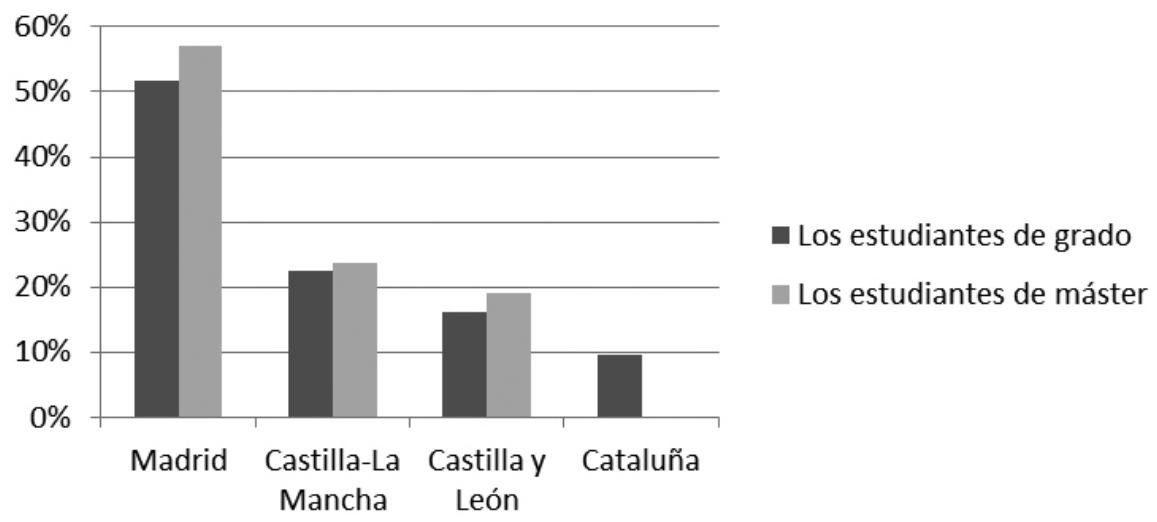

Gráfico 6. Si considera que hay un lugar en España donde se habla el español más correcto, escriba el nombre de la ciudad o de la región.

Es interesante notar que un porcentaje aún más bajo de los estudiantes tanto de grado $(29,3 \%)$ como de máster $(22,6 \%)$ piensan que en algún sitio de España se habla el español menos correcto (Gráfico 7). Por lo tanto, el 70,7 \% de los informantes de grado y el 77,4 \% de los informantes de máster consideran que no existe ningún lugar donde se hable el español menos correcto. Los informantes que dieron respuestas concretas sobre el lugar donde se habla ese español menos correcto ( 21 estudiantes de grado y 11 estudiantes de máster) escribieron que se trataba de Andalucía, Galicia y Cataluña (Gráfico 8). La gran mayoría de los estudiantes de máster (81,8 \%) consideran que el español menos correcto se habla en Andalucía, mientras que el resto opina que se trata de Galicia. Los estudiantes de grado optan por Andalucía y Cataluña en la misma medida $(42,9 \%)$, mientras que el resto elige Galicia (14,3 \%). Las respuestas individuales como Madrid, el País Vasco o Murcia no figuran en el gráfico. 
¿Considera que hay un lugar en España donde se habla el español menos correcto?

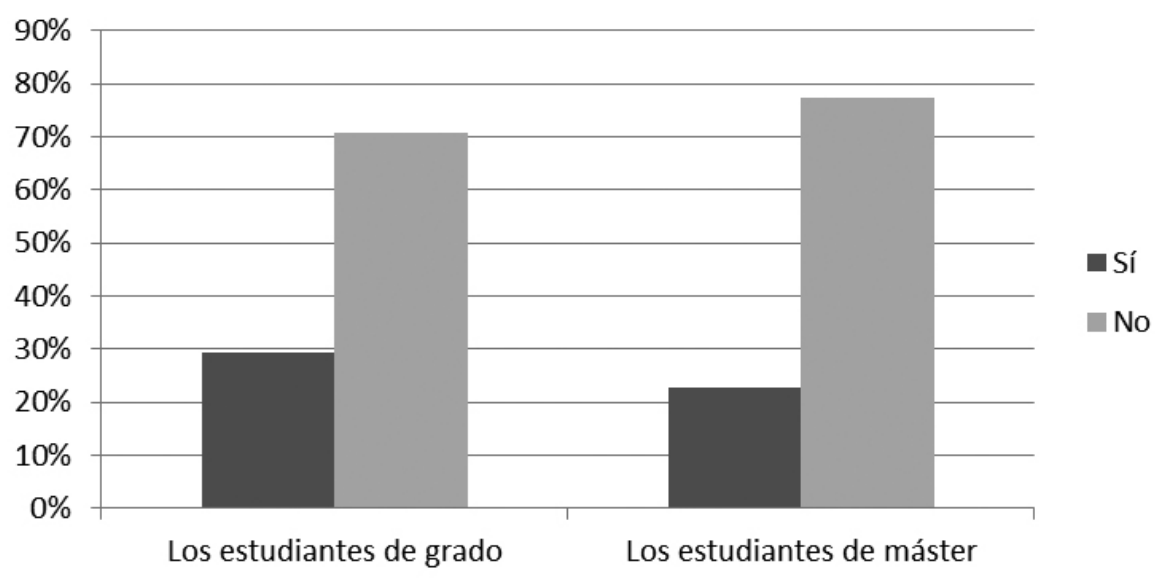

Gráfico 7. ¿Considera que hay un lugar en España donde se habla el español menos correcto?

\section{Si considera que hay un lugar en España donde se habla el español menos correcto, escriba el nombre de la ciudad o de la región.}

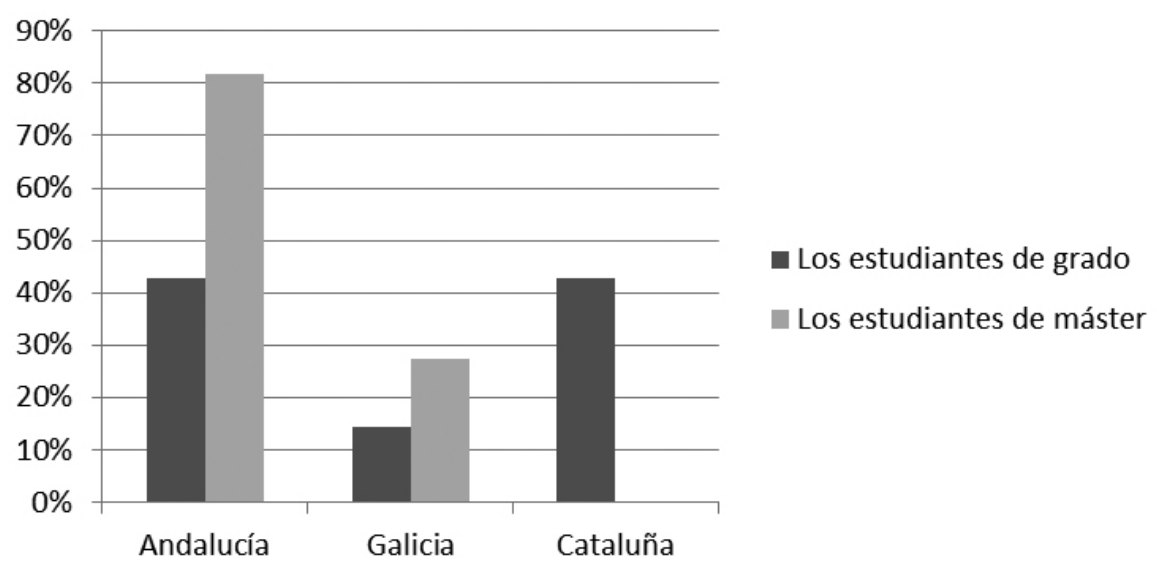

Gráfico 8. Si considera que hay un lugar en España donde se habla el español menos correcto, escriba el nombre de la ciudad o de la región. 
(4) Las diferencias entre el español madrileño en relación con otras regiones españolas y los países bispanoamericanos

A la pregunta sobre las diferencias que existen entre el español que se habla en Madrid y el que se habla en otras regiones españolas respondieron 80 estudiantes de grado y 54 estudiantes de máster. Todos los informantes consideran que entre estas variantes existen algunas diferencias. Del Gráfico 9 se puede concluir que los estudiantes de máster optan en mayor medida por todos los niveles de las diferencias (el nivel fonético, morfosintáctico y léxico-semántico), mientras que más estudiantes de grado eligen la respuesta "No lo sé". El orden de las diferencias sigue el mismo entre estudiantes de grado y de máster: la mayoría opta por las diferencias en el nivel fonético, luego siguen las diferencias léxico-semánticas y, finalmente, las morfosintácticas.

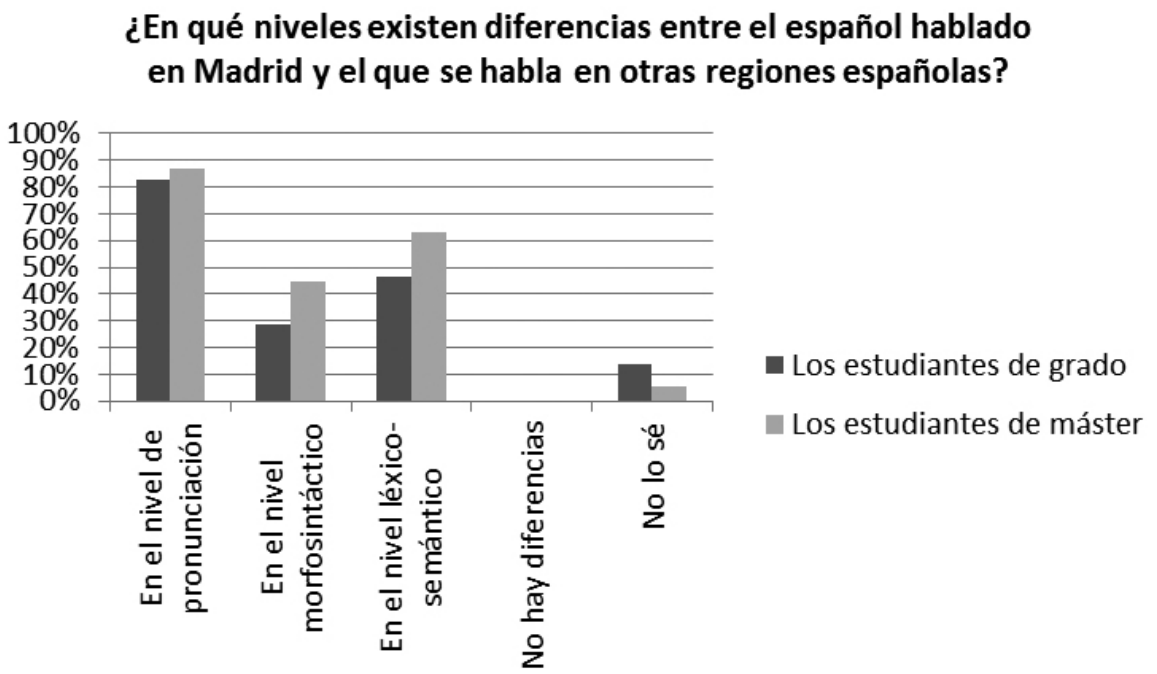

Gráfico 9. ¿En qué niveles existen diferencias entre el español hablado en Madrid y el que se habla en otras regiones españolas?

El mismo número de estudiantes respondieron a la pregunta sobre las diferencias entre el español que se habla en Madrid y el que se habla en los países de Hispanoamérica. Como en la pregunta anterior, no hay ningún informante que considere que estas variantes no se diferencian. El Gráfico 10 muestra la distribución de sus respuestas: los estudiantes de grado eligen las diferencias fonéticas en primer lugar, luego siguen las diferencias léxico-semánticas y 


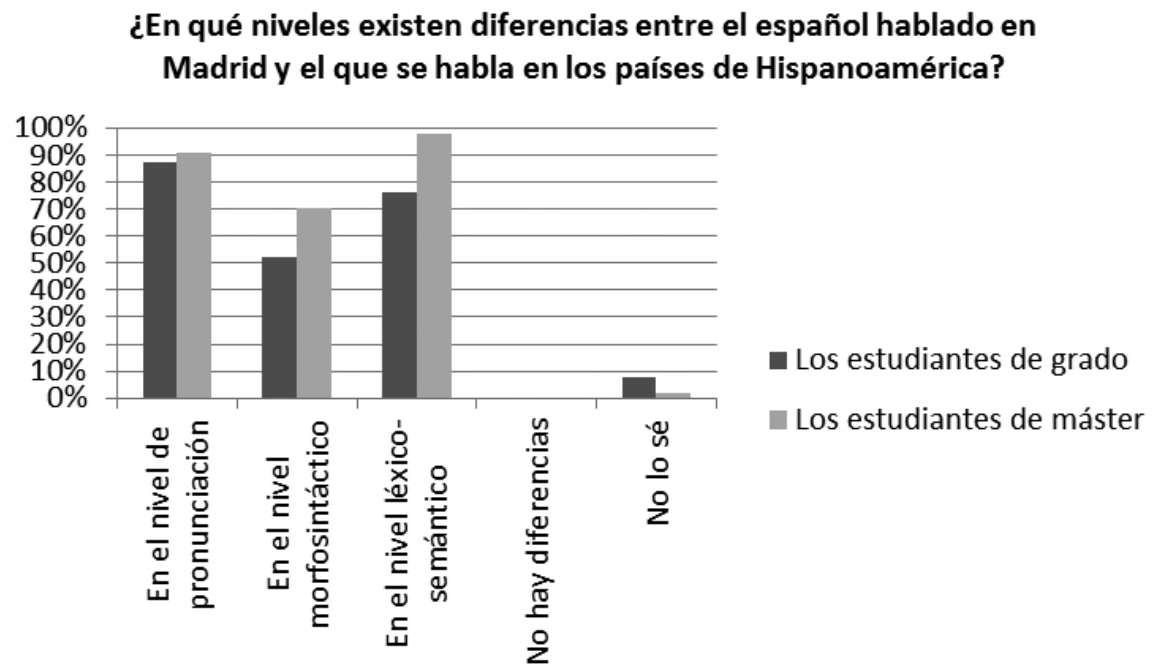

Gráfico 10. ¿En qué niveles existen diferencias entre el español hablado en Madrid y el que se habla en los países de Hispanoamérica?

finalmente las morfosintácticas. El orden de las respuestas de los estudiantes de máster es un poco diferente: más del $90 \%$ optan por las diferencias léxicosemánticas $(98,1 \%$ ) y fonéticas $(90,7 \%)$, mientras que un $70,4 \%$ opinan que se trata de las diferencias morfosintácticas también. Asimismo, solamente un estudiante de máster eligió la respuesta "No lo sé".

Si comparamos estos dos gráficos, podemos afirmar que los informantes tanto de grado como de máster concluyen que hay más diferencias en todos los niveles entre el español de Hispanoamérica y el peninsular que entre las variedades que se hablan en diferentes regiones españolas.

\section{(5) El español estándar}

A la pregunta sobre la lengua estándar que se habla en los países de Hispanoamérica, la gran mayoría de los estudiantes de grado ( $80 \%$ ) y de máster $(83,3 \%)$ responden que cada país tiene su variedad estándar. Casi el mismo porcentaje de los estudiantes de grado y de máster, un poco más del $11 \%$, consideran que hay solamente un estándar -el español de España. El 8,8 \% de los estudiantes de grado y el 5,6\% de los estudiantes de máster no saben contestar a esa pregunta. 


\section{¿Cuál es el español estándar que se habla en los países de Hispanoamérica?}

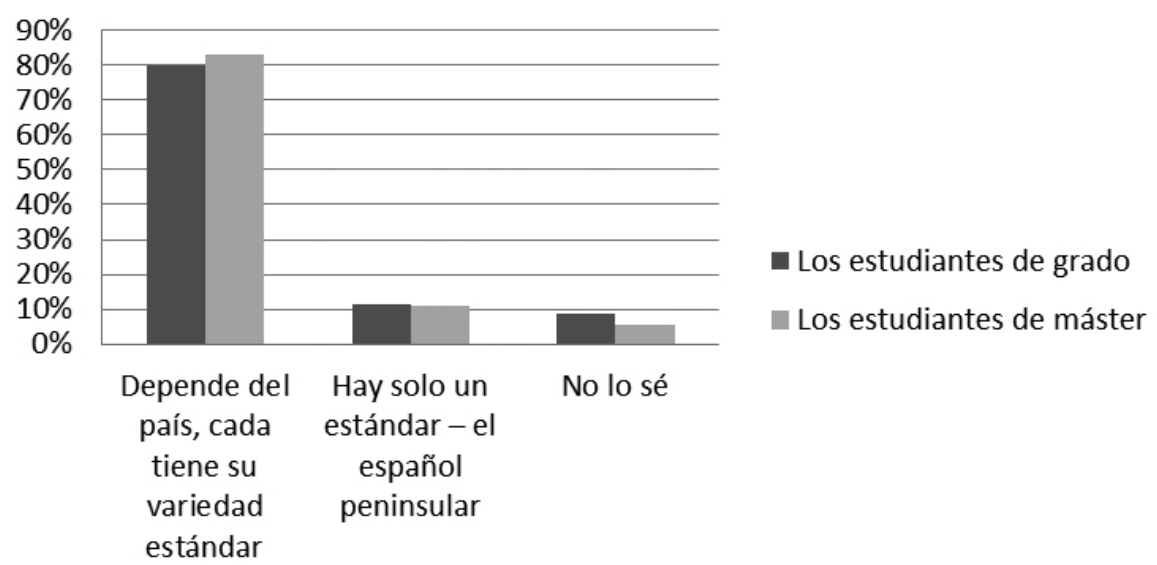

Gráfico 11. ¿Cuál es el español estándar que se habla en los países de Hispanoamérica?

Además, más del 50\% de los informantes de grado y de máster piensan que dos hablantes de español, uno de España y otro de Hispanoamérica, se entienden bien, pero en su habla existen diferencias importantes en el nivel fonético y léxico $(59,5 \%$ y $57,4 \%)$. El $38 \%$ de los estudiantes de grado opina que el

\section{¿Cómo se entienden un hablante de España y un hablante de algún país de Hispanoamérica?}

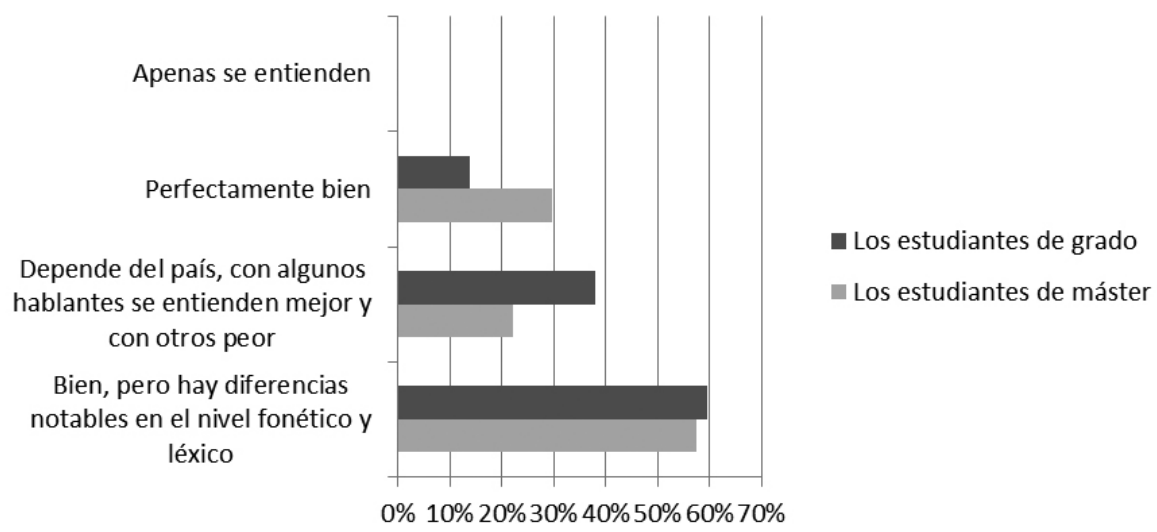

Gráfico 12. ¿Cómo se entienden un hablante de España y un hablante de algún país de Hispanoamérica? 
entendimiento de estos dos hablantes depende del país de Hispanoamérica, mientras que en el máster este porcentaje disminuye y equivale al 22,2 \%. En comparación con los informantes de grado, más informantes de máster $(29,6 \%)$ consideran que estos dos hablantes se entienden perfectamente bien. No hay ningún estudiante que piense que estos hablantes apenas se entienden.

\section{(6) El español más correcto en Hispanoamérica}

Más de dos tercios de los informantes de grado y de máster $(67,5 \%$ y 79,2 \%) opinan que el español que se habla en España no es más correcto que el español que se habla en los países de Hispanoamérica. El resto o no sabe contestar a esa pregunta $(7,5 \%$ y $5,7 \%)$ o consideran que el español peninsular es más correcto $(25 \%$ y $14,8 \%)$.

\section{¿Considera que el español que se habla en España es más} correcto que el español que se habla en Hispanoamérica?

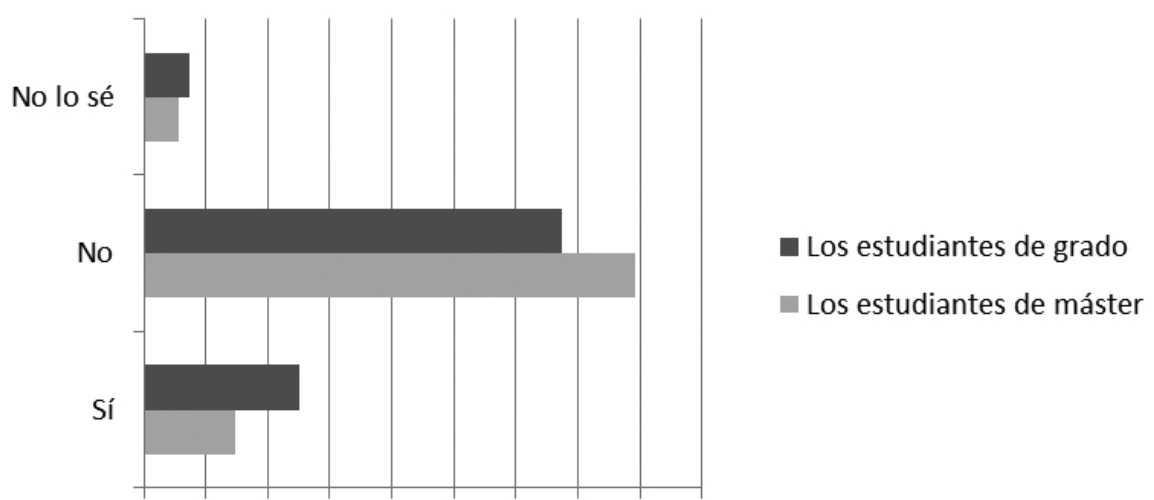

0\% 10\% 20\% 30\% 40\% 50\% 60\% 70\% 80\% 90\%

Gráfico 13. ¿ ¿ Considera que el español que se habla en España es más correcto que el español que se habla en Hispanoamérica?

Con estas respuestas concuerdan las respuestas a la pregunta sobre el país hispanoamericano donde se habla el español más correcto (Gráfico 14). La mayoría de los estudiantes tanto de grado (52,8 \%) como de máster (50 \%) opina que en todos los países de Hispanoamérica se habla igualmente bien. Los estudiantes de grado destacan el Perú (18,1 \%), México (16,7\%) y Colombia $(5,6 \%)$ como los países hispanoamericanos donde se habla el español más correcto, mientras que los estudiantes de máster optan por los mismos países pero en un orden diferente: en el primer lugar está México (24 \%), 
luego siguen Colombia ( $18 \%$ ) y el Perú ( 4 \%). En cuanto al resto de los países, un pequeño porcentaje de los estudiantes elige Argentina, Chile, Puerto Rico y Venezuela. El resto de los países de Hispanoamérica no fue seleccionado ni una sola vez y, por lo tanto, no figuran en el gráfico.

En su opinión, ¿en qué país hispanoamericano se habla el español más correcto?

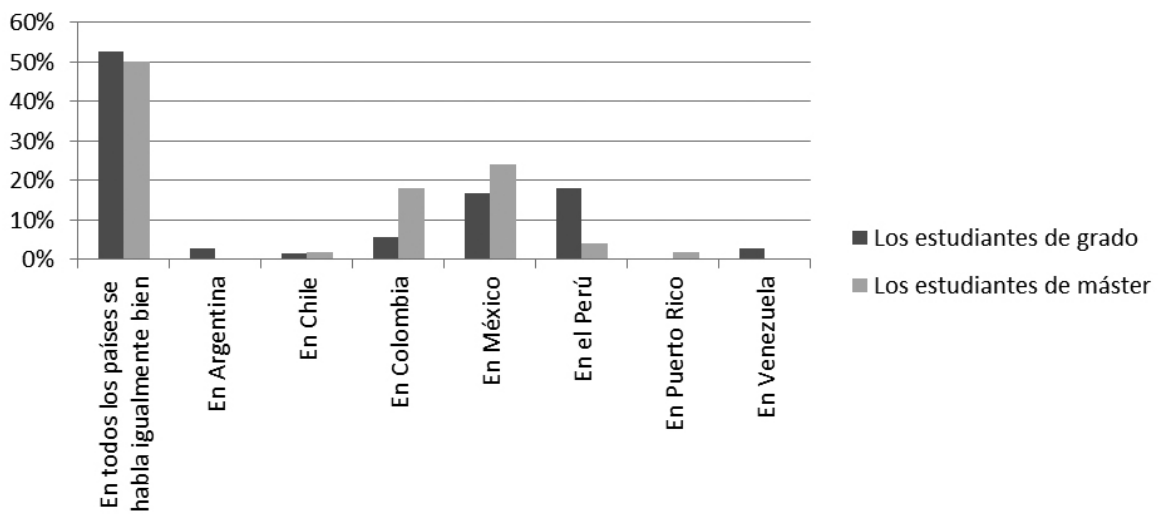

Gráfico 14. En su opinión, ¿̇en qué país hispanoamericano se habla el español más correcto?

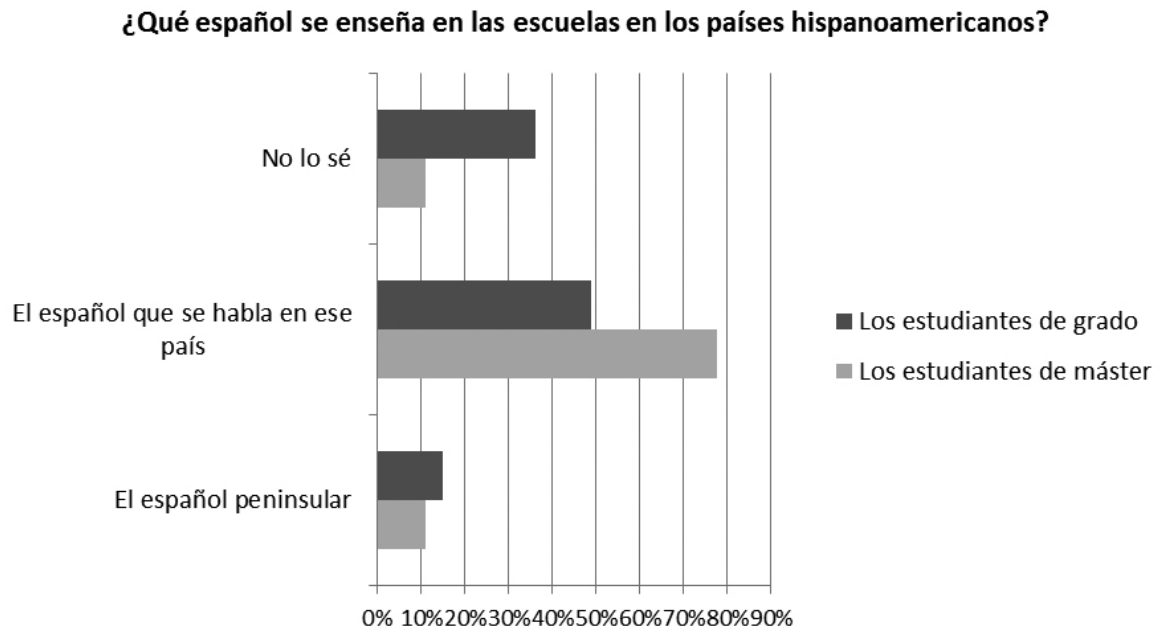

Gráfico 15. ¿Qué variedad del español se enseña en las escuelas en los países hispanoamericanos? 
A la pregunta sobre qué español se enseña en los países de Hispanoamérica, la mayoría de los estudiantes contesta que se trata del español que se habla en ese país (48,8 \% para los estudiantes de grado y 77,8 \% para los estudiantes de máster). El mismo porcentaje de los estudiantes de máster o no sabe responder a esa pregunta o considera que se trata del español peninsular (11,1\%). Más de un tercio de los estudiantes de grado no sabe la respuesta a esta pregunta $(36,3 \%)$, mientras que el $15 \%$ piensa que se trata del español de España.

\section{Conclusión}

Los resultados muestran varios aspectos que resaltan. Primero, se puede notar que entre los estudiantes existe cierta inseguridad lingüística ya que respondieron de una manera diferente a dos preguntas (una directa y otra indirecta para averiguar las actitudes): si existe un "mejor" español y un "peor" español (Gráfico 5 y 7) donde entre el 42 y el 45 por ciento de los informantes cree que hay territorios donde se habla un español más correcto (Madrid, Castilla), pero al mismo tiempo el $70 \%$ de los informantes cree que no hay un lugar donde se hable un español menos correcto. Aquí, por un lado, se puede ver la influencia de la política lingüística de la RAE que últimamente insiste en la igualdad entre las variedades mencionadas. Por otro lado, es interesante que los estudiantes, desde el punto de vista sociolingüístico, no discriminen ninguna de las variedades. Sin embargo, entre todas las variedades del español, la de Madrid se destaca como la representativa y la más reconocida, lo que se puede explicar, asimismo, por el hecho de que España es un país europeo y, por lo tanto, mucho más reconocible para los estudiantes croatas.

En segundo lugar, existe una opinión general entre los españoles de que el andaluz es una variedad desviada del español o un español mal hablado (PRECAVES $\mathrm{XXI}^{1}$, 2008). Es un estereotipo típico de España donde una variedad (en este caso el castellano) se prefiere frente a las otras. De este modo, si los estudiantes de la Lengua y Literaturas Hispánicas de Zagreb consideran que existe una variedad menos correcta, optan por el andaluz. Si tomamos en cuenta el hecho de que las variedades hispanoamericanas son más parecidas al andaluz, se esperaría que los estudiantes eligieran también estas variedades como menos correctas. Sin embargo, ese no es el caso, ya que se insiste en la igualdad entre el castellano y las variedades hispanoamericanas (más del $70 \%$ de los estudiantes).

1 El proyecto PRECAVES XXI (Proyecto para el estudio de creencias y actitudes hacia las variedades del español en el siglo XXI), dirigido por Cestero Mancera y Paredes, se inició en 2013, con la realización de 124 encuestas en la zona central de España. 
Por último, diríamos que los resultados muestran perfectamente la fuerza y la influencia de los conocimientos obtenidos durante la formación. Durante los estudios crecen no solo los conocimientos sobre la lengua sino las actitudes y valoraciones hacia ciertas variedades. Se nota que, además de los conocimientos sobre la lengua, los estudiantes extranjeros, en este caso croatas, adoptan no solo la lengua sino también las actitudes y los estereotipos que existen generalmente entre los españoles. Las actitudes hacia ciertas variedades pueden ser los estereotipos reflejados por el contacto con España y con los españoles, ya que el $38 \%$ de los estudiantes nunca ha visitado ningún país hispano y entre los que visitaron algún país hispano casi el $50 \%$ visitó una vez España.

En el futuro sería interesante comparar los datos obtenidos por los estudiantes de español como L2 con los resultados de PRECAVES XXI, u otros parecidos, para ver hasta qué punto difieren las apreciaciones entre los nativos que evalúan su lengua materna y los que la evalúan como una L2.

\section{Bibliografía}

Alvar López, M. (1983): «Español en Santo Domingo y Español de España. Análisis de algunas actitudes lingüísticas». En Lingüistica española actual, 2. http://www.cervantesvirtual.com/servlet/SirveObras/p184/ 024505297678238329 76613/index.htm (15-05-2016).

Alvar López, M. (1986): Hombre, etnia, estado, actitudes lingüísticas en Hispanoamérica. Madrid: Gredos.

Blas Arroyo, J. L. (2005): Sociolingüística del español. Madrid: Cátedra.

Cestero Mancera, A. M.; Paredes, F. (2015): «Creencias y actitudes hacia las variedades normativas del español actual. Primeros resultados del Proyecto PRECAVES-XXI». En Kim Potowski (ed.), Spanish in context, vol. 12:2. Amsterdam: John Benjamins, 255-279.

Erdösová, Z. (2011): «El español de México en los ojos de sus hablantes. Un estudio desde la sociolingüística y la dialectología perceptiva». En Lengua y voz, 1. Universidad Autónoma del Estado de México, 57-81.

García de Paredes, E. (2012): «Los retos de la codificación normativa del español: cómo conciliar los conceptos de español pluricéntrico y español panhispánico». En Franz Lebsanft (ed.), El español ¿desde las variedades a la lengua pluricéntrica?. Frankfurt-Madrid: Iberoamericana-Vervuert, 281-312. 
García Marcos, F. (1993): Nociones de sociolingüística. Barcelona: Octaedro.

Haugen, E. (1996): «Dialect, Language, Nation». En American Antbropologist, New Series, 68 (4). http://www.jstor.org/stable/670407 (10-05-2016).

Lope Blanch, J. M. (1968): El español de América. Madrid: Ediciones Alcalá.

Lope Blanch, J. M. (1995): «La norma lingüística y la lengua literaria». En AIH, Actas XII. http://cvc.cervantes.es/literatura/aih/pdf/12/aih_12_1_028. $\operatorname{pdf}(25-05-2016)$.

Moreno Fernández, F. (1992): «Norma y prestigio en el español de América. Apuntes para una planificación de la lengua española». En Revista de Filología Española, LXXII: $345^{-359 . ~}$

Moreno Fernández, F. (ed.). (1993): La división dialectal del español de América. Alcalá de Henares: Servicio de Publicaciones de la Universidad de Alcalá.

Moreno Fernández, F. (2005): Historia social de las lenguas de España. Barcelona: Ariel.

Moreno Fernández, F. (2009): Principios de sociolingüistica y sociología del lenguaje. Barcelona: Ariel.

Preston, D. (2002): «Perceptual Dialectology: Aims, methods and findings». En Jan Berns and Jaap Van Marle (ed.) Present-day Dialectology: Problems and Findings. Berlin: Mouton de Gruyter.

Schmid, D. (2014): «Percepción y actitud lingüística: el castellano serrano en contraste con el castellano costeño en elEcuador». En $e$-CRIT3224, 6.http:// e-crit3224.univ-fcomte.fr/download/3224-ecrit/document/numero_6/ 11.-de--sire--e-schmid_def-1.pdf (20-04-2016). 
Maša Musulin, Metka Bezlaj

University of Zagreb

\section{Perception of the Varieties of Spanish by Students of Spanish Language and Literature at the University of Zagreb}

Keywords: linguistic varieties, standard language, norm, Spanish, University Studies of Spanish Language

In 2016 a survey was carried out among students of Spanish Language and Literature at the University of Zagreb. The survey consisted of two parts and in this work we present the data obtained by the questionnaire, in which the students' sociolinguistic knowledge of the Spanish language and its varieties was ascertained. The questionnaire was completed anonymously and voluntarily by 154 participants. The results showed that the Zagreb students recognize, among all the varieties of Spanish, the one from Madrid as the representative and the most identifiable, which can be explained by the fact that Spain is a European country and, therefore, much more accessible for Croatian students but also because of the influence of the RAE and its lexicographical works that predominate in the teaching of Spanish. A certain percentage of the questioned students believe that there is a less correct variety of Peninsular Spanish - Andalusian. The results also show the influence not only of the linguistic knowledge obtained during studies but furthermore the attitudes towards certain varieties. It is noted that Croatian students acquire not only the language but also sometimes the attitudes and stereotypes that generally exist among Spaniards. That means that the attitudes towards certain varieties are not necessary the result of their own evaluation but the stereotypes reflected by the greater contact with Spain and Spaniards. 
Maša Musulin, Metka Bezlaj

Univerza v Zagrebu

\section{Zaznavanje različic španščine pri študentih Španskega jezika in književnosti Univerze $v$ Zagrebu}

Ključne besede: jezikovne različice, knjižna norma, standardni jezik, španščina, univerzitetni študij španskega jezika in književnosti

Leta 2016 je Filozofska fakulteta Univerze v Zagrebu izvedla anketo med študenti španskega jezika in književnosti. V pričujočem prispevku predstavljava izsledke iz tistega dela vprašalnika, ki je preverjal sociolingvistično znanje o rabi španščine in njenih jezikovnih različic. Vprašalnik, ki je obsegal dva dela, je anonimno in prostovoljno izpolnilo 154 študentov. Rezultati ankete so pokazali, da zagrebški študentje pripisujejo različici španščine, ki je prisotna v Madridu, med vsemi jezikovnimi različicami najbolj prepoznavno in značilno vlogo. To ugotovitev utemeljujemo z dejstvom, da hrvaški študenti Španijo lažje prepoznavajo kot evropsko državo ter da je zlasti v izobraževanju prisoten močan vpliv Španske kraljeve akademije in njenih leksikografskih izdaj, ki so močno prisotne pri poučevanju španščine na Hrvaškem. Nekaj vprašanih je menilo, da obstaja manj pravilna različica - andaluzijske - španščine. Izsledki so pokazali višjo raven jezikovnega znanja dodiplomskih študentov, ki z leti študija ne razvijajo le znanja o jeziku, temveč tudi odnos in sodbe do nekaterih jezikovnih različic. V določeni meri bi na hrvaške študente španščine lahko vplivali splošni predsodki Špancev do omenjenih pojavov. Sklepamo lahko, da odnos do določenih jezikovnih različic določajo zlasti predsodki, ki jih prinaša okrepljen stik s Španijo in Španci, osebne vrednostne sodbe do določenih jezikovnih različic pa imajo le okrnjen vpliv. 